\title{
28 Research Square \\ Intraspecific Variation In Plant Economic Traits Predicts Trembling Aspen Resistance To A Generalist Insect Herbivore
}

Clay J. Morrow ( $\sim$ morrow5@wisc.edu )

University of Wisconsin - Madison https://orcid.org/0000-0002-3069-3296

Samuel J. Jaeger

University of Wisconsin-Madison

Richard L. Lindroth

University of Wisconsin-Madison

\section{Research Article}

Keywords: bioassays, chemical defense, ecological strategy, gypsy moth, Populus tremuloides

Posted Date: July 21st, 2021

DOI: https://doi.org/10.21203/rs.3.rs-650965/v1

License: (c) (i) This work is licensed under a Creative Commons Attribution 4.0 International License. Read Full License 


\section{Abstract}

Patterns of trait expression within some plant species have recently been shown to follow patterns described by the leaf economics spectrum paradigm. Resistance to herbivores is also expected to covary with leaf economics traits. We selected multiple mature Populus tremuloides genotypes from a common garden to assess whether aspen leaf economics patterns follow those observed among species globally. We also evaluated leaf economics strategies in the context of insect resistance by conducting bioassays to determine the effects of plant traits on preference and performance of Lymantria dispar. We found that: 1) intraspecific trait patterns of $P$. tremuloides parallel those exhibited by the interspecific leaf economics spectrum, 2) herbivores preferred leaves from genotypes with resource-acquisitive strategies, and 3) herbivores also performed best on genotypes with resourceacquisitive strategies. We conclude that a leaf economics spectrum that incorporates defense traits is a useful tool for explaining intraspecific patterns of variation in plant strategies, including resistance to herbivores.

\section{Introduction}

Plants exhibit phenotypic variation, both within and among species, that results in variable resistance to phytophagy. Metabolic, allocational, and genetic tradeoffs between growth and defense traits contribute to this variation and have been well-documented (Züst et al. 2015; Züst and Agrawal 2017; Heckman et al. 2019). Growth and defense traits, however, do not exist in isolation. Rather, they are single components of larger phenotypic expression networks. Patterns of trait covariation are typically complex, with tradeoffs occurring among multiple traits simultaneously (Züst and Agrawal 2017; Cole et al. 2021). Accordingly, hypotheses addressing variation in plant defense strategies, especially those that incorporate growth-defense associations, would benefit by considering co-expression of resistance and non-resistance traits alike.

Plant traits are intercorrelated in predictable ways across a broad array of species, worldwide. Mass-based rates of photosynthesis are positively associated with leaf nitrogen and phosphorous content, dark respiration, and specific leaf area (SLA). Developed by Wright et al. (2004), the leaf economics spectrum (LES) summarizes these patterns as a tradeoff between resource-conservative and resource-acquisitive strategies of adaptation across biomes and has proven useful for predicting the distribution of plant traits and fitness (Donovan et al. 2011; Reich 2014). Differentiation of plant strategies arises partly because of investment costs associated with one trait or function over another. Predictions that plants in resource-poor environments should grow slowly and invest in defense traits (Coley et al. 1985; Coley 1987) have been generally supported (Endara and Coley 2011). Growth-defense tradeoffs, in particular, are also expected to occur in plants exposed to strong herbivory pressure. For example, fast-growing plants are expected to sustain more herbivore damage than their slow-growing counterparts (Price 1991; Herms and Mattson 1992). Recognition of the ubiquity of growth-defense tradeoffs and the importance of herbivore resistance to plant fitness has led to the recent incorporation of defense traits, specifically phytochemical resistance, into the LES paradigm (Agrawal 2020).

If increased growth is associated with decreased herbivore resistance, then herbivores should both prefer and perform best on growth-optimized plants (Levins and MacArthur 1969; Price 1991; Mayhew 1997). This means that insect preference and performance should be aligned and that growth-associated plant traits drive these outcomes. Little evidence exists, however, that insect preference and performance are linked to each other or to plant growth in general. Some sessile insects, which are closely associated with their host plants, do exhibit a preferenceperformance linkage (e.g., Fritz et al. 2000). Additionally, Gripenberg et al. (2010) demonstrated a link between ovipositional preference and offspring survival across 21 plant-insect systems. Yet, studies of preference- 
performance relationships have been limited in scope and evidence of a broad linkage remains largely inconsistent. For example, investigations of insect preference and performance within the same experimental system are rare and host selection behaviors other than oviposition preference have rarely been considered (Gripenberg et al. 2010). Moreover, research on insect performance relative to plant growth was relatively scarce a decade ago (Cornelissen et al. 2008; Gripenberg et al. 2010), and has not improved appreciably since.

The capacity to explain plant variation and herbivore resistance with a small number of LES traits is appealing, but may be scale-dependent. The applicability of the LES across taxonomic and ecological scales has been assessed in several recent studies. Anderegg et al. (2018) found that some leaf economics traits exhibited different correlations when compared within versus among species (962 genera). They concluded that, due to phenotypic plasticity, the LES may not be indicative of plant strategies at smaller taxonomic scales. Agrawal (2020) found similar inconsistencies in Asclepias across populations, species, and environmental gradients; at some scales, no LES correlations were found. It remains unclear under what conditions patterns of intraspecific trait co-expression differ from patterns among species. Phenotypic variation within plant species, and effects on their communities and ecosystems, can be substantial in certain systems (Des Roches et al. 2018; Koricheva and Hayes 2018; Westerband et al. 2021). Co-expression of plant phenotype and its impact on herbivores is key to understanding intraspecific strategies of resistance.

This research used an ecologically and economically important tree-insect system to investigate the impacts of trait co-expression on resistance to herbivores. Trembling aspen (Populus tremuloides) is a foundation tree species with an expansive range across northern and western North America (Mitton and Grant 1996). The species exhibits exceptional levels of phenotypic variation (Mitton and Grant 1996; Cole et al. 2021), making it an ideal candidate for assessing leaf economics patterns. The gypsy moth (Lymantria dispar) is an invasive forest defoliator (McManus and Csóka 2007), for which aspen is a preferred host (Liebhold et al. 1997). Trembling aspen exhibits a wide range of heritable variation in phytochemical defense that reduces performance of gypsy moths (Hemming and Lindroth 2000; Osier et al. 2000; Donaldson and Lindroth 2007). This experimental system, therefore, provided an ideal opportunity to assess the utility of the LES at the intraspecific level. Trembling aspen is known to exhibit growth-defense tradeoffs (Cole et al. 2016, 2021) but whether its trait expression is consistent with other LES patterns is unknown. The system also provided a unique opportunity to test the preference-performance linkage with an herbivore underrepresented in prior research. Gypsy moths are mobile, leaf-chewing, generalist lepidopterans and exhibit host selection as larvae (Doane and McManus 1981). These types of insects are largely absent from the preference-performance literature (Gripenberg et al. 2010).

This study evaluated the LES paradigm, including chemical defense traits, at the intraspecific level and assessed its ability to explain preference and performance patterns of gypsy moths on trembling aspen. We addressed the following questions: 1) Are patterns of intraspecific trait expression consistent with predictions of the LES? 2) Do herbivores preferentially feed on aspen with resource acquisitive strategies? 3) Are herbivores advantaged by feeding on resource acquisitive plants over resource conservative plants?

\section{Materials And Methods}

To investigate the effects of leaf economics strategies on resistance to herbivory, we conducted two concurrent bioassays comparing larval preference and performance among aspen clones with varying growth rates. We assessed host selection and growth of larvae as indicators of aspen resistance, as both metrics influence gypsy moth fitness. We selected aspen clones to represent a wide range of variation in growth over a six-year period, 
thereby enhancing the probability of detecting intraspecific patterns of leaf economics traits and their effects on larval preference and performance.

\section{Aspen genotype selection}

This study used 36 aspen genotypes from a common garden population of 492 genotypes. We established the garden by collecting rootstock from throughout Wisconsin (358 km latitude range, $186 \mathrm{~km}$ longitude range) and planting root sprouts with $2.5 \times 2.5 \mathrm{~m}$ spacing at the University of Wisconsin-Madison Arlington Agricultural Research Station (43.32 $\mathrm{N}$ latitude, $89.33^{\circ} \mathrm{W}$ longitude) in 2010 . One year prior to the study reported here, we selected experimental genotypes to maximize variation in growth over the garden's 7-year life. To achieve desired variation, we randomly selected twelve genotypes, with three replicate trees, from each of the bottom, middle and top deciles of the population's growth distribution and classified them as low-, moderate- and high-growth genotypes, respectively.

\section{Insect bioassays}

We performed two bioassays to evaluate gypsy moth preference for, and performance on, aspen genotypes from different growth classes. We obtained multiple gypsy moth egg masses from the USDA APHIS insect production facility (Buzzards Bay, MA), incubated $\left(25-18^{\circ} \mathrm{C}, 50-70 \%\right.$ humidity, 16:8 L:D cycle), hatched, and reared them to third and fourth instars for use in bioassays. Larvae were fed a standardized diet of non-experimental $P$. tremuloides leaves and gypsy moth wheat germ diet (MP Biomedicals) prior to experimental deployment.

Preference bioassays were designed to test host selection of gypsy moth larvae in response to aspen phenotype. We maintained third instars (69-90 mg) without food for 24 hours preceding the experiment, after which time they were placed individually into petri dishes $(15 \mathrm{~cm}$ diameter) with two leaves. Dishes contained pairs of leaves such that larvae had a choice between genotypes from different growth classes (i.e., low vs moderate, low vs. high, moderate vs. high). We replicated each growth class pairing with 12 distinct genotype pairs, for a total of 36 dishes in the bioassay. We replicated each genotype twice and assigned genotype pairs randomly. Larvae fed freely within dishes for 60 hours.

Leaves used in the preference bioassays were obtained from a single representative tree for each genotype. On the morning that trials were begun, we collected a single proleptic short shoot from each tree and kept them refrigerated until use. Two bioassay leaves were randomly selected from each shoot, weighed, and measured for specific leaf area (SLA). We inserted petioles of the bioassay leaves through a hole punched into lids of $2.0 \mathrm{~mL}$ microcentrifuge tubes containing water and placed them into their experimental dishes prior to larval introduction. We then developed genotype-specific water content calibrations with remaining short shoot leaves by comparing leaf weights before and after vacuum drying. We estimated initial dry mass of bioassay leaves by subtracting genotype-specific water content from initial leaf weights. We measured final dry mass of bioassay leaves upon conclusion of the trials.

At the end of the preference bioassays, we removed larvae and leaves from dishes and determined genotype preference by comparing the mass consumed from each leaf (i.e., final mass - initial mass). We used the proportional consumption of a leaf by a larva as our metric of preference (i.e., leaf mass consumed $\div$ total mass consumed) We then created a genotype-specific preference index by averaging preference for each genotype across dishes in which they occurred. 
Performance bioassays were designed to assess the growth of gypsy moth larvae in response to aspen growth strategy. The experiment followed a nested factorial design where three replicate trees of 12 genotypes were nested within each of the three growth classes for a total of 108 trees. We selected and weighed sets of ten newly molted third instars and deployed them to trees in the common garden. Fine mesh bags, secured with zip ties, contained larvae on northeast-facing branches at approximately $1.4 \mathrm{~m}$ above ground. After ten days, we collected, counted, sexed (Lavenseau 1982), vacuum dried, and weighed surviving larvae. As a performance metric, we estimated average relative growth rate (RGR) for larvae on each tree with the formula (final mass - initial mass) $\div$ (initial mass $x 10$ days). We estimated initial dry mass of larvae from fresh weights with the formula initial aggregate weight $\div 10$ larvae $\times 0.13 \mathrm{mg}+0.27 \mathrm{mg}$, as determined via calibration from additional third instars from our colony. Immediately before deployment of larvae, we collected four to six mature leaves from each experimental branch for quantification of morphological and phytochemical traits.

\section{Phenotypic trait measurements}

We quantified aspen growth to evaluate its relationships with expression of traits and resistance to herbivores. We measured basal area increment $\left(\mathrm{BAI}=\left(\pi r_{2018}^{2}-\pi r_{2010}^{2}\right) \div 8\right.$; at $1.4 \mathrm{~m}$ above ground) over the lifespan of the trees as our primary metric of growth. Recognizing that leaf economics traits may be linked as well to short-term growth rates, we measured growth during the year the study took place. Because large plants exhibit greater absolute growth than do small plants during the same interval, it is important to relativize growth rate estimates by size when comparing trees of very different sizes. Accordingly, we calculated 1-year relative growth rates as $\left(\mathrm{RGR}=\ln \left(\pi r_{2018}^{2} \div \pi r_{2017}^{2}\right)\right)$, which accounts for variation in initial size.

We also quantified leaf morphological and chemical traits to evaluate their effects on herbivore resistance and their relationships with growth. We used leaves collected during the performance bioassays for quantification of leaf traits for all experimental trees. We first measured leaf area with a LI-COR 3100 area meter. Next, we vacuum dried, weighed, and ground leaves (ball mill) for phytochemical analyses. We measured salicinoid phenolic glycosides as chemical resistance traits in this study because of their documented deleterious effects on gypsy moths and other Lepidoptera (Donaldson and Lindroth 2007; Lindroth and St. Clair 2013). Condensed tannins, which do not negatively impact lepidopterans, were not measured. We extracted salicinoids from leaf tissue into methanol and quantified them by UPLC mass spectrometry (Rubert-Nason et al. 2017). Our chemical standards for salicinoid analyses consisted of commercially available salicin and lab-purified salicortin, tremulacin, and tremuloidin. We measured nitrogen concentrations with a ThermoFlash carbon/nitrogen elemental analyzer. All chemical concentrations are expressed as a percentage of leaf dry weight. Finally, we calculated specific leaf area by dividing total leaf area by total mass of all leaves collected from a tree.

\section{Statistical analyses}

To test the hypothesis that gypsy moth larvae should prefer resource acquisitive aspen, we performed multifactor analysis of variance (ANOVA) and pairwise t-tests comparing the mass consumed between leaves within dishes in the preference bioassays. All treatment specifications (dish treatment, genotype identity, and growth class) were included as factors in both analyses. We then performed multiple linear regression analysis relating a leaf's preference index with aspen phenotype to determine which traits best explain larval preference.

To test the hypothesis that gypsy moth larvae should grow faster on resource acquisitive aspen genotypes, we performed further multi-factor ANOVAs and pairwise t-tests of performance assay data, comparing larval relative 
growth rates among aspen growth classes and genotypes. We also performed multiple linear regression analysis of larval relative growth rates to determine which traits best explain larval performance.

Finally, we conducted a redundancy analysis (RDA) to investigate the effects of aspen phenotype on herbivore resistance. RDA is a constrained ordination that partitions variation of a multivariate regression. We used larval growth on, and preference for, genotypes as our multivariate response indicative of resistance. We included genotype averages of all traits as predictors. We assessed variation in larval metrics attributable to variation in trait expression using the RDA loadings. We also graphically assessed alignment of intraspecific trait variation with the LES.

All statistical analyses were performed using the R statistical software package (R Core Team 2020). We used a significance threshold of 0.05 for all hypothesis tests and considered results marginally significant for P-values between 0.05 and 0.10 . We performed stepwise selection to obtain linear models that best explain (i.e., lowest AIC) insect metrics with tree traits and growth class. We also calculated adjusted $R^{2}\left(R^{2}\right.$ adj $)$ to assess overall fit of the selected models. RDA was performed using the rda function from the vegan $\mathrm{R}$ package and statistical significance was determined via permutation test (Oksanen et al. 2020).

\section{Results}

Here, we first present variation observed among growth classes for each aspen trait. Next, we explore resistance to gypsy moths by comparing insect metrics among aspen growth classes and genotypes, and by assessing associations between insect metrics and plant traits. Finally, we describe correlated patterns of leaf economics traits among genotypes and their associations with herbivore resistance.

\section{Aspen trait variation}

Trait expression differed among aspen genotypes from the three different growth classes. Of all traits measured, only BAI differed among all three growth classes (Fig. 1A). Genotypes in the high-growth class had lower RGRs than those in the low-growth class (Fig. 1B). Of the four salicinoids, salicortin and tremulacin were most abundant and concentrations of both were lowest for high-growth genotypes (Fig. 1D-E). In contrast, tremuloidin concentrations were very low but, higher among high-growth genotypes than among low-growth genotypes (Fig. 1F). Salicin concentrations were similarly low but did not differ among growth classes (Fig. 1C). Notably, one lowgrowth genotype had extraordinarily high concentrations of all four salicinoids when compared with other lowgrowth genotypes (Fig. 1C-F). Nitrogen did not differ among growth classes (Fig. 1G) and had the lowest variation of any trait. SLA was lower for low-growth genotypes than for high-growth genotypes (Fig. 1H).

\section{Herbivore resistance bioassays}

Larvae preferred to feed on leaves from fast-growing aspen (Fig. 2). Larvae consumed twice as much tissue from high-growth than from low-growth genotypes, and 53\% more from high-growth than from moderate-growth genotypes. Larvae did not discriminate between low-growth and moderate-growth genotypes. BAI and total salicinoids were positively and negatively associated with leaf consumption, respectively (Table 1, Supp. Figure 1). Together, these traits best explained larval preference for a genotype $\left(R^{2}\right.$ adj $\left.=0.23\right)$, with salicinoids explaining more than BAI (Table 1). 
Table 1

Best model (lowest AIC) for explaining larval preference for aspen genotypes. Rows represent model terms. Columns represent regression coefficients, standard error of the coefficients, regression t-statistics, type

II sum of squares, degrees of freedom, F-statistics (SS/MSE), and corresponding P-values. The P-value for the t- and F-statistics are identical.

\begin{tabular}{|lccccccc|}
\hline & Coef & SE & t & SS & df & F & P \\
\hline (Intercept) & 0.64 & 0.17 & 3.8 & & & & 0.0005 \\
\hline BAl & 0.02 & 0.02 & 1.8 & 0.23 & 1 & 3.4 & 0.0758 \\
\hline Total salicinoids & -0.06 & 0.02 & -2.6 & 0.45 & 1 & 6.5 & 0.0154 \\
\hline
\end{tabular}

Larvae also performed well on resource acquisitive aspen (Fig. 3). Larvae grew faster on high-growth genotypes than on moderate-growth genotypes. Interestingly, larval growth rates were intermediate, and most variable, on lowgrowth genotypes. SLA and tremulacin were positively and negatively associated with larval growth, respectively (Table 2, Supp. Figure 2). These traits, along with growth class, best explained variation in larval performance $\left(\mathrm{R}^{2}\right.$ adj $\left.=0.38\right)$ and SLA explained the most (Table 2). Increased nitrogen was also associated with increased larval growth (Supp. Figure 2G) but the strong correlation between nitrogen and SLA (Table 3) made their effects largely redundant.

Table 2

Best model (lowest AIC) for explaining larval growth performance for aspen genotypes. Formatting follows from Table 1. Values for moderate and high growth classes are relative to that of the low growth class, which is captured by the intercept term. ANOVA results for Growth class factor: $S S=0.17, D f=2, F=2.6, P=0.090$.

\begin{tabular}{|lccccccc|}
\hline & Coef & SE & t & SS & df & F & P \\
\hline (Intercept) & 0.25 & 0.27 & 0.9 & & & & 0.362 \\
\hline SLA & 3.88 & 1.07 & 3.6 & 0.43 & 1 & 13.1 & 0.001 \\
\hline Tremulacin & -0.07 & 0.04 & -1.7 & 0.10 & 1 & 3.0 & 0.091 \\
\hline Class:mod & -0.16 & 0.08 & -2.1 & & & & 0.043 \\
\hline Class:high & -0.03 & 0.08 & -0.4 & & & & 0.728 \\
\hline
\end{tabular}


Table 3

Correlation matrix for aspen traits and larval metrics among genotypes. Column and row headings correspond to

basal area increment; short-term relative growth rate of aspen; concentrations of salicin, salicortin, tremulacin, tremuloidin, and nitrogen; specific leaf area; larval relative growth rate; and larval preference. Cells represent

Pearson's correlation coefficient and superscript symbols represent statistical significance $(+: 0.05<\mathrm{P}<0.1, *: 0.01$ $<\mathrm{P}<0.05, * *: \mathrm{P}<0.01)$.

\begin{tabular}{|c|c|c|c|c|c|c|c|c|c|}
\hline & BAI & RGR & Salicin & Salicortin & Tremulacin & Tremuloidin & $N$ & SLA & $\begin{array}{l}\text { larval } \\
\text { RGR }\end{array}$ \\
\hline RGR & $-0.29^{+}$ & & & & & & & & \\
\hline Salicin & 0.21 & -0.05 & & & & & & & \\
\hline Salicortin & $-0.40^{*}$ & 0.17 & -0.04 & & & & & & \\
\hline Tremulacin & $-0.28^{+}$ & 0.18 & 0.25 & $0.90^{\star *}$ & & & & & \\
\hline Tremuloidin & $0.30^{+}$ & -0.08 & $0.90^{\star \star}$ & -0.18 & 0.13 & & & & \\
\hline $\mathrm{N}$ & 0.17 & $-0.30^{+}$ & $0.31^{+}$ & -0.27 & -0.18 & $0.30^{+}$ & & & \\
\hline SLA & $0.40^{*}$ & -0.21 & $0.32^{+}$ & -0.22 & -0.15 & $0.40^{*}$ & $0.50^{\star *}$ & & \\
\hline larval RGR & 0.23 & -0.20 & -0.03 & $-0.31^{+}$ & $-0.30^{*}$ & 0.10 & $0.40^{*}$ & $0.50^{\star \star}$ & \\
\hline larval pref. & $0.40^{+}$ & -0.21 & -0.2 & $-0.40^{*}$ & $-0.40^{*}$ & -0.21 & 0.06 & 0.05 & 0.23 \\
\hline
\end{tabular}

\section{Leaf economics trait patterns}

Aspen genotypes exhibited trait correlations consistent with growth-resistance tradeoffs and LES patterns (Table 3). BAI was negatively correlated with salicortin and positively correlated with SLA. Short-term aspen RGR was not significantly correlated with any other traits. Salicortin and tremulacin were strongly positively correlated, as were salicin and tremuloidin. SLA was positively correlated with both tremuloidin and nitrogen.

Redundancy analysis revealed that leaf economics strategies were associated with resistance to herbivory, and that genotypes exhibited substantial variation in these strategies both within and among aspen growth classes (Fig. 4). Larval preference and performance were not strongly correlated (Table 4) and were affected differently by aspen traits. Larval preference for aspen genotypes was most closely associated with high BAl and low levels of the salicinoids salicortin and tremulacin. In contrast, larval performance (growth rate) was determined by levels of tremulacin and nitrogen, as well as SLA. These multivariate results align with those from univariate analyses of the two bioassays. Aspen traits explained $35 \%$ of the variation in gypsy moth resistance, of which salicortin and BAI explained the most (Supp. Table 1).

Growth class alone was not a reliable predictor of leaf economics strategy. Although high-growth genotypes were more likely to have acquisitive strategies than those in other classes, this tendency was too weak to be differentiable (Fig. 4). High levels of genotypic variation within growth classes contributed to substantial phenotypic overlap among classes.

\section{Discussion}


This researched aimed to evaluate the LES paradigm at the level of intraspecific trait variation, and its potential to explain insect herbivore resistance. Our results demonstrate that the paradigm can indeed be useful for explaining intraspecific variation in plant strategies. Fast-growing, resource-acquisitive aspen had higher specific leaf area, higher foliar nitrogen concentrations, and lower foliar salicinoid concentrations, resulting in low herbivore resistance, when compared with more resource-conservative strategies. No strong insect preference-performance linkage was found, and aspen traits affected the two indicators of herbivore resistance somewhat differently. Larvae preferred to feed on aspen with low salicinoid concentrations and fast growth. Larvae also performed well on aspen with low salicinoid concentrations, but performance was primarily associated with nitrogen and specific leaf area. In summary, leaf economics traits were useful indicators of plant resistance strategies.

Observed trait patterns within $P$. tremuloides align with those found among species worldwide. Intraspecific LES patterns have been demonstrated in a variety of species (e.g., common reed: Hu et al. 2015; coffee: Martin et al. 2017). Yet, recent comparisons of the LES across diverse ecological and taxonomic scales reveal that trait correlations can be scale-dependent. For example, in their meta-analysis of 2,031 species, Anderegg et al. (2018) found that, though directions remain consistent, magnitudes of trait correlations with LMA (i.e., ${ }^{\frac{1}{\text { SLA }}}$ ) and nitrogen vary among taxonomic scales. Other research also shows that conformation with LES patterns can depend upon spatial scales (Messier et al. 2017). We could not evaluate spatial dependence but trait patterns driven by genetics are unlikely spatially structured in Wisconsin aspen due to lack of population structure (Cole 2005; Barker et al. 2019b).

This work also reveals that incorporation of defense traits can benefit assessments of the LES at the intraspecific level. Recent research shows that plant defense is correlated with traditional LES traits within and among species. For example, Helianthus defense is correlated with interspecific LES strategy (Mason and Donovan 2015). Similarly, across species of spiny plants, physical defenses are associated with leaf productivity, whereas chemical defenses are not (Armani et al. 2020). Both chemical and physical defense traits are correlated with LES traits within Asclepias syriaca, but not among different Asclepias species (Agrawal 2020). In short, a growing body of literature suggests that the utility of incorporating herbivore defense into the LES paradigm is species- or contextspecific. A major limitation of a defense-integrated LES paradigm is the sheer diversity of defense types, which makes comparisons across species challenging. Even so, because herbivores are ubiquitous and formative components of plant communities, incorporation of herbivore defense traits will likely enhance the value and function of LES models.

Our results show that not only are defense traits associated with leaf economics strategies, but so too are defense outcomes. While it is clear that intraspecific plant strategies result in tradeoffs between growth and defense traits in many systems (Endara and Coley 2011; Züst and Agrawal 2017), to our knowledge, none of the recent evaluations of plant defense and the LES include measures of resistance outcomes. Covarying effects of plant traits on herbivore fitness are well known (e. g., Simpson and Raubenheimer 2001) and defense traits are particularly well-studied (e.g., Gong and Zhang 2014). This work further establishes how those traits are integrated across a spectrum of intraspecific functional strategies and the consequences thereof for trophic interactions.

Intraspecific covariation in defense and conventional LES traits has important ecological and evolutionary consequences in aspen and other Populus species. Foliar nitrogen and salicinoids govern the preference, performance, distribution, and abundance of herbivorous insects, as well as their rates of defoliation (Donaldson and Lindroth 2007; Falk et al. 2018). They also influence the structure of herbivorous insect communities (Bangert 
et al. 2006; Barker et al. 2018, 2019a) and dynamics of multi-trophic interactions (Bailey et al. 2006). More recently, work with experimental aspen stands documented that intraspecific competition alters the consequences of genotypic growth-defense tradeoffs, leading to divergent genetic architecture of aspen populations (Cope et al. 2021).

The relationship between host plant selection and performance of insect herbivores remains equivocal. The most comprehensive meta-analysis of preference-performance relationships to date found that survival, but not weight or development time, are associated with host preference (21 comparable plant-insect systems; Gripenberg et al. 2010). For gypsy moths and numerous other insects, however, preference and performance appear unrelated (e.g., Valladares and Lawton 1991; Underwood 1994; Fritz et al. 2000).

Gypsy moth larvae engage in host plant selection by dispersing from unsuitable hosts (Capinera and Barbosa 1976; Lance and Barbosa 1981). These decisions appear to be made primarily in response to chemical defenses; Solari et al. (2002) found that gypsy moth larvae respond strongly to deterrent stimuli (i.e., nicotine) but not to classical nutrition stimuli. Our work reaffirms these findings. Gypsy moths selected hosts according to salicinoid concentrations and largely ignored performance-associated nutrients (i.e., nitrogen).

In conclusion, our work reveals that the leaf economics spectrum can be useful for describing patterns of association among plant functional traits, - including herbivore resistance traits - at the intraspecific level. In trembling aspen, genotypes of resource acquisitive plants had high specific leaf area, high nitrogen concentrations, and low salicinoid concentrations compared with resource conservative genotypes. This trait combination elicited higher herbivore preference, and performance, relative to insects on resource conservative plants. Patterns of phenotypic relationships identified in this research suggest that growth-associated traits render individuals more susceptible to herbivore attack.

\section{Declarations}

\section{Acknowledgements}

This research was conducted on ancestral land of the Ho-Chunk Nation. We thank Chris Cole and Mark Zierden for assistance with chemical analyses and Chris Cole and Jenn Riehl for genotype verification. S. Jaeger's work was supported by a UW Holstrom Environmental Research Fellowship.

Funding: This research was funded by USDA National Institute of Food and Agriculture grants 2016-7013-25088 and WIS01651.

Conflicts of interest: None.

Consent to participate: Not applicable.

Consent for publication: Not applicable.

Availability of data and material: The datasets generated in this research are available from the corresponding author upon reasonable request.

Code availability: The code used to analyze these data is available from the corresponding author upon reasonable request. 
Author's contributions: CJM, SJ, and RLL conceived and designed the experiments. RLL secured funding. CJM and SJ conducted fieldwork, lab work, and analyzed the data. CJM and RLL wrote the manuscript.

\section{References}

1. Agrawal AA (2020) A scale-dependent framework for trade-offs, syndromes, and specialization in organismal biology. Ecology 101:1-24. https://doi.org/10.1002/ecy.2924

2. Anderegg LDL, Berner LT, Badgley G et al (2018) Within-species patterns challenge our understanding of the leaf economics spectrum. Ecol Lett 21:734-744. https://doi.org/10.1111/ele.12945

3. Armani M, Goodale UM, Charles-Dominique T et al (2020) Structural defence is coupled with the leaf economic spectrum across saplings of spiny species. Oikos. https://doi.org/10.1111/oik.06960

4. Bailey JK, Wooley SC, Lindroth RL, Whitham TG (2006) Importance of species interactions to community heritability: a genetic basis to trophic-level interactions. Ecol Lett 9:78-85. https://doi.org/10.1111/j.14610248.2005.00844.x

5. Bangert RK, Turek RJ, Rehill B et al (2006) A genetic similarity rule determines arthropod community structure. Mol Ecol 15:1379-1391. https://doi.org/10.1111/j.1365-294X.2005.02749.x

6. Barker HL, Holeski LM, Lindroth RL (2018) Genotypic variation in plant traits shapes herbivorous insect and ant communities on a foundation tree species. PLoS One 13:1-21.

https://doi.org/10.1371/journal.pone.0200954

7. Barker HL, Holeski LM, Lindroth RL (2019a) Independent and interactive effects of plant genotype and environment on plant traits and insect herbivore performance: A meta-analysis with Salicaceae. Funct Ecol 33:939-941. https://doi.org/10.1111/1365-2435.13165

8. Barker HL, Riehl JF, Bernhardsson C et al (2019b) Linking plant genes to insect communities: Identifying the genetic bases of plant traits and community composition. Mol Ecol 28:4404-4421. https://doi.org/10.1111/mec.15158

9. Capinera JL, Barbosa P (1976) Dispersal of first-instar gypsy moth larvae in relation to population quality. Oecologia 26:53-60. https://doi.org/10.1007/BF00345652

10. Cole CT (2005) Allelic and population variation of microsatellite loci in aspen (Populus tremuloides). New Phytol 167:155-164. https://doi.org/10.1111/j.1469-8137.2005.01423.x

11. Cole CT, Morrow CJ, Barker HL et al (2021) Growing up aspen: ontogeny and trade-offs shape growth, defence and reproduction in a foundation species. Ann Bot 1-13. https://doi.org/10.1093/aob/mcaa070

12. Cole CT, Stevens MT, Anderson JE, Lindroth RL (2016) Heterozygosity, gender, and the growth-defense tradeoff in quaking aspen. Oecologia 181:381-390. https://doi.org/10.1007/s00442-016-3577-6

13. Coley PD (1987) Interspecific variation in plant anti-herbivore properties: the role of habitat quality and rate of disturbance. New Phytol 106:251-263. https://doi.org/10.1111/j.1469-8137.1987.tb04693.x

14. Coley PD, Bryant JP, Chapin FS (1985) Resource availability and plant antiherbivore defense. Adv Sci 230:895-899

15. Cope OL, Keefover-Ring K, Kruger EL, Lindroth RL (2021) Growth-defense tradeoffs shape population genetic composition in an iconic forest tree species

16. Cornelissen T, Wilson Fernandes G, Vasconcellos-Neto J (2008) Size does matter: variation in herbivory between and within plants and the plant vigor hypothesis. Oikos 117:1121-1130. 
https://doi.org/10.1111/j.0030-1299.2008.16588.x

17. Des Roches S, Post DM, Turley NE et al (2018) The ecological importance of intraspecific variation. Nat Ecol Evol 2:57-64. https://doi.org/10.1038/s41559-017-0402-5

18. Doane CC, McManus ML (1981) The gypsy moth: research toward integrated pest management. US Department of Agriculture

19. Donaldson JR, Lindroth RL (2007) Genetics, environment, and their interaction determines efficacy of chemical defense in trembling aspen. Ecology 88:729-739. https://doi.org/10.1890/06-0064

20. Donovan LA, Maherali H, Caruso CM et al (2011) The evolution of the worldwide leaf economics spectrum. Trends Ecol Evol 26:88-95. https://doi.org/10.1016/j.tree.2010.11.011

21. Endara MJ, Coley PD (2011) The resource availability hypothesis revisited: a meta-analysis. Funct Ecol 25:389-398. https://doi.org/10.1111/j.1365-2435.2010.01803.x

22. Falk MA, Lindroth RL, Keefover-Ring K et al (2018) Genetic variation in aspen phytochemical patterns structures windows of opportunity for gypsy moth larvae. Oecologia 187:471-482.

https://doi.org/10.1007/s00442-018-4160-0

23. Fritz RS, Crabb BA, Hochwender CG (2000) Preference and performance of a gall-inducing sawfly: a test of the plant vigor hypothesis. Oikos 89:555-563. https://doi.org/10.1034/j.1600-0706.2000.890315.x

24. Gong B, Zhang G (2014) Interactions between plants and herbivores: a review of plant defense. Acta Ecol Sin 34:325-336. https://doi.org/10.1016/j.chnaes.2013.07.010

25. Gripenberg S, Mayhew PJ, Parnell M, Roslin T (2010) A meta-analysis of preference-performance relationships in phytophagous insects. Ecol Lett 13:383-393. https://doi.org/10.1111/j.1461-0248.2009.01433.x

26. Heckman RW, Halliday FW, Mitchell CE (2019) A growth-defense trade-off is general across native and exotic grasses. Oecologia 191:609-620. https://doi.org/10.1007/s00442-019-04507-9

27. Hemming JDC, Lindroth RL (2000) Effects of phenolic glycosides and protein on gypsy moth (Lepidoptera: Lymantriidae) and forest tent caterpillar (Lepidoptera: Lasiocampidae) performance and detoxication activities. Environ Entomol 29:1108-1115. https://doi.org/10.1603/0046-225x-29.6.1108

28. Herms WJ, Mattson DA (1992) The dilemma of plants: to grow or defend. Q Rev Biol 67:283-335

29. Hu YK, Pan X, Liu GF et al (2015) Novel evidence for within-species leaf economics spectrum at multiple spatial scales. Front Plant Sci 6:1-9. https://doi.org/10.3389/fpls.2015.00901

30. Koricheva J, Hayes D (2018) The relative importance of plant intraspecific diversity in structuring arthropod communities: a meta-analysis. Funct Ecol 32:1704-1717. https://doi.org/10.1111/1365-2435.13062

31. Lance D, Barbosa P (1981) Host tree influences on the dispersal of first instar gypsy moths, Lymantria dispar (L.). Ecol Entomol 6:411-416. https://doi.org/10.1111/j.1365-2311.1981.tb00632.x

32. Lavenseau L (1982) Determination of the sex of caterpillars without dissection. Int J Insect Morphol Embryol 11:359-362. https://doi.org/10.1016/0020-7322(82)90025-3

33. Levins R, MacArthur R (1969) An hypothesis to explain the incidence of monophagy. Ecology 50:910-911. https://doi.org/https://doi.org/10.2307/1933709

34. Liebhold AM, Gottschalk KW, Mason DA, Bush RR (1997) Forest susceptibility to the gypsy moth. J For 95:2024. https://doi.org/10.1093/jof/95.5.20

35. Lindroth RL, St. Clair SB (2013) Adaptations of quaking aspen (Populus tremuloides Michx.) for defense against herbivores. For Ecol Manage 299:14-21. https://doi.org/10.1016/j.foreco.2012.11.018 
36. Martin AR, Rapidel B, Roupsard O et al (2017) Intraspecific trait variation across multiple scales: the leaf economics spectrum in coffee. Funct Ecol 31:604-612. https://doi.org/10.1111/1365-2435.12790

37. Mason CM, Donovan LA (2015) Does investment in leaf defenses drive changes in leaf economic strategy? A focus on whole-plant ontogeny. Oecologia 177:1053-1066. https://doi.org/10.1007/s00442-014-3177-2

38. Mayhew PJ (1997) Adaptive patterns of host-plant selection by phytophagous insects. Nord Soc Oikos 79:417-428. https://doi.org/https://doi.org/10.2307/3546884

39. McManus M, Csóka G (2007) History and impact of gypsy moth in North America and comparison to recent outbreaks in Europe. Acta Silv Lign Hung Acta Silv Lign Hung 3:47-64

40. Messier J, McGill BJ, Enquist BJ, Lechowicz MJ (2017) Trait variation and integration across scales: is the leaf economic spectrum present at local scales? Ecography 40:685-697. https://doi.org/10.1111/ecog.02006

41. Mitton JB, Grant MC (1996) Genetic variation and the natural history of quaking aspen. Bioscience 46:25-31. https://doi.org/10.2307/1312652

42. Oksanen J, Blanchet FG, Friendly M et al (2020) vegan: community ecology package

43. Osier TL, Hwang S-Y, Lindroth RL (2000) Within- and between-year variation in early season phytochemistsry of quaking aspen (Populus tremuloides Michx.) clones. Biochem Syst Ecol 28:197-208

44. Price PW (1991) The plant vigor hypothesis and herbivore attack. Oikos 62:244-251. https://doi.org/https://doi.org/10.2307/3545270

45. R Core Team (2020) R: a Language and environment for statistical computing

46. Reich PB (2014) The world-wide "fast-slow" plant economics spectrum: a traits manifesto. J Ecol 102:275301. https://doi.org/10.1111/1365-2745.12211

47. Rubert-Nason K, Keefover-Ring K, Lindroth RL et al (2017) Purification and analysis of salicinoids. Curr Anal Chem 14:423-429. https://doi.org/10.2174/1573411014666171221131933

48. Simpson SJ, Raubenheimer D (2001) The geometric analysis of nutrient - allelochemical interactions: a case study using locusts. Ecology 82:422-439. https://doi.org/10.1890/0012-

9658(2001)082[0422:TGAONA]2.0.CO;2

49. Solari P, Cerboneschi A, Masala C et al (2002) Chemoreception in larvae of the moth Lymantria dispar. Ital J Zool 69:305-312. https://doi.org/10.1080/11250000209356474

50. Underwood DLA (1994) Intraspecific variability in host plant quality and ovipositional preferences in Eucheira socialis (Lepidoptera: Pieridae). Ecol Entomol 19:245-256. https://doi.org/10.1111/j.1365-

2311.1994.tb00416.x

51. Valladares G, Lawton JH (1991) Host-plant selection in the holly leaf-miner: does mother know best? J Anim Ecol 60:227-240. https://doi.org/10.2307/5456

52. Westerband AC, Funk JL, Barton KE (2021) Intraspecific trait variation in plants: a renewed focus on its role in ecological processes. Ann Bot 127:397-410. https://doi.org/10.1093/aob/mcab011

53. Wright IJ, Reich PB, Westoby M et al (2004) The worldwide leaf economics spectrum. Nature 428:821-827

54. Züst T, Agrawal AA (2017) Trade-offs between plant growth and defense against insect herbivory: an emerging mechanistic synthesis. Annu Rev Plant Biol 68:513-534. https://doi.org/10.1146/annurev-arplant-042916040856

55. Züst T, Rasmann S, Agrawal AA (2015) Growth-defense tradeoffs for two major anti-herbivore traits of the common milkweed Asclepias syriaca. Oikos 124:1404-1415. https://doi.org/10.1111/oik.02075 


\section{Tables}

Table 4 is not available with this version.

\section{Figures}
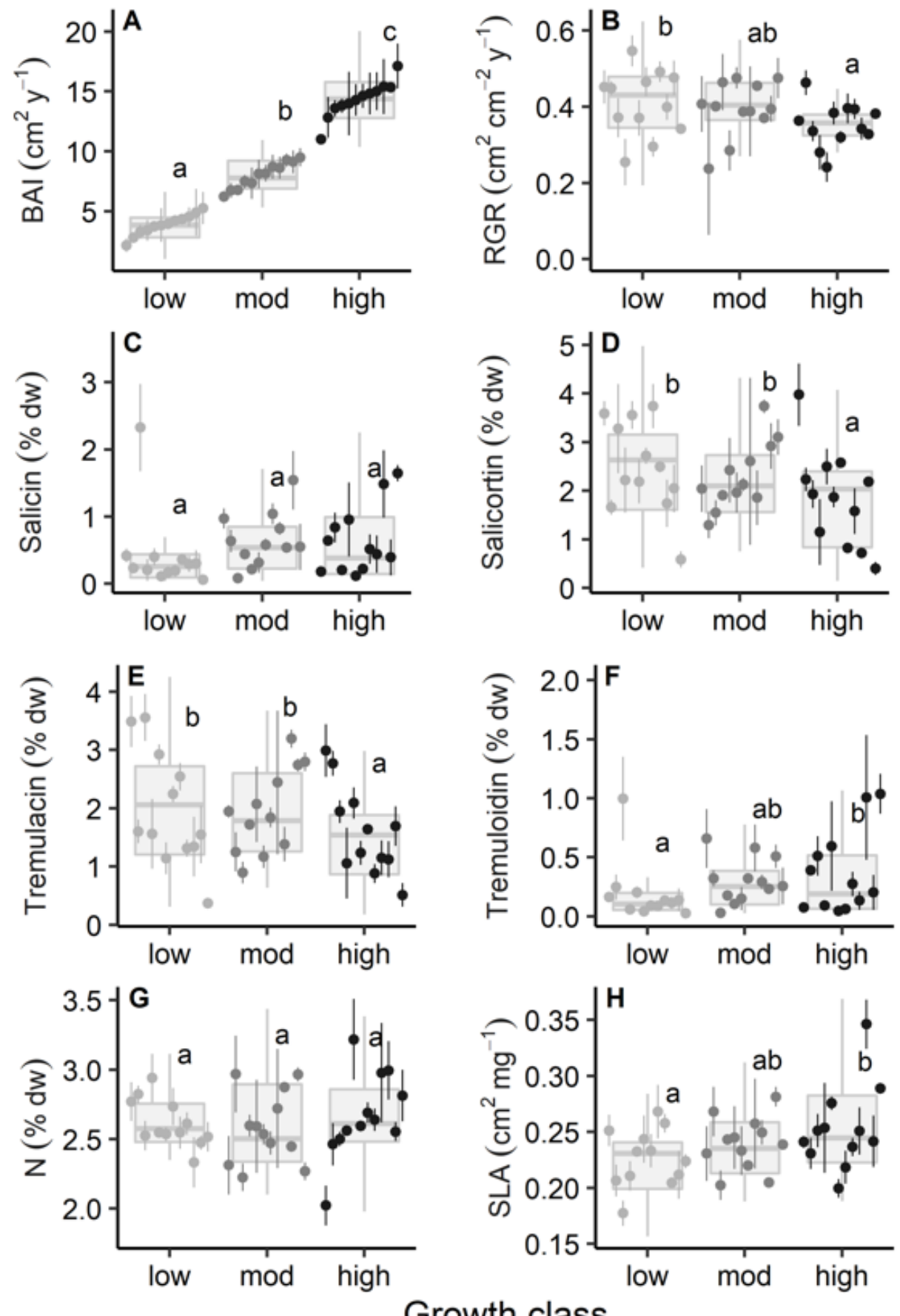

Growth class

Figure 1

Trait variation among Populus tremuloides growth classes. Points represent genotype means for each trait and error bars represent +/- 1 standard error. Boxes show quartiles for each growth class and whiskers show the range, excluding outliers. Lower case letters represent statistically distinct groupings among growth classes (Tukey's least 
significant difference). Phytochemical concentrations are expressed as percent dry weight. Genotypes are shown in order of ascending BAI for all panels.

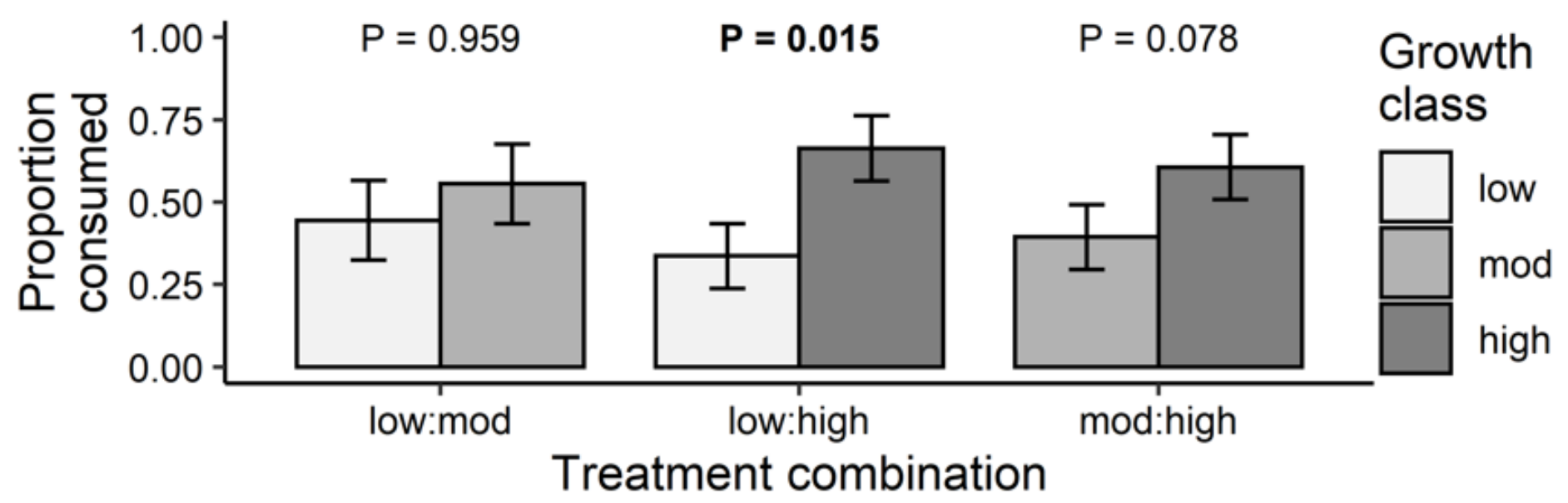

Figure 2

Feeding preferences of larval Lymantria dispar for pairwise combinations of aspen leaves from low, moderate, and high growth classes. Bars represent leaf mass consumed from a leaf within a dish, as a proportion of total tissue consumed. Error bars represent +/- 1 standard error and P-values correspond to pairwise t-tests.

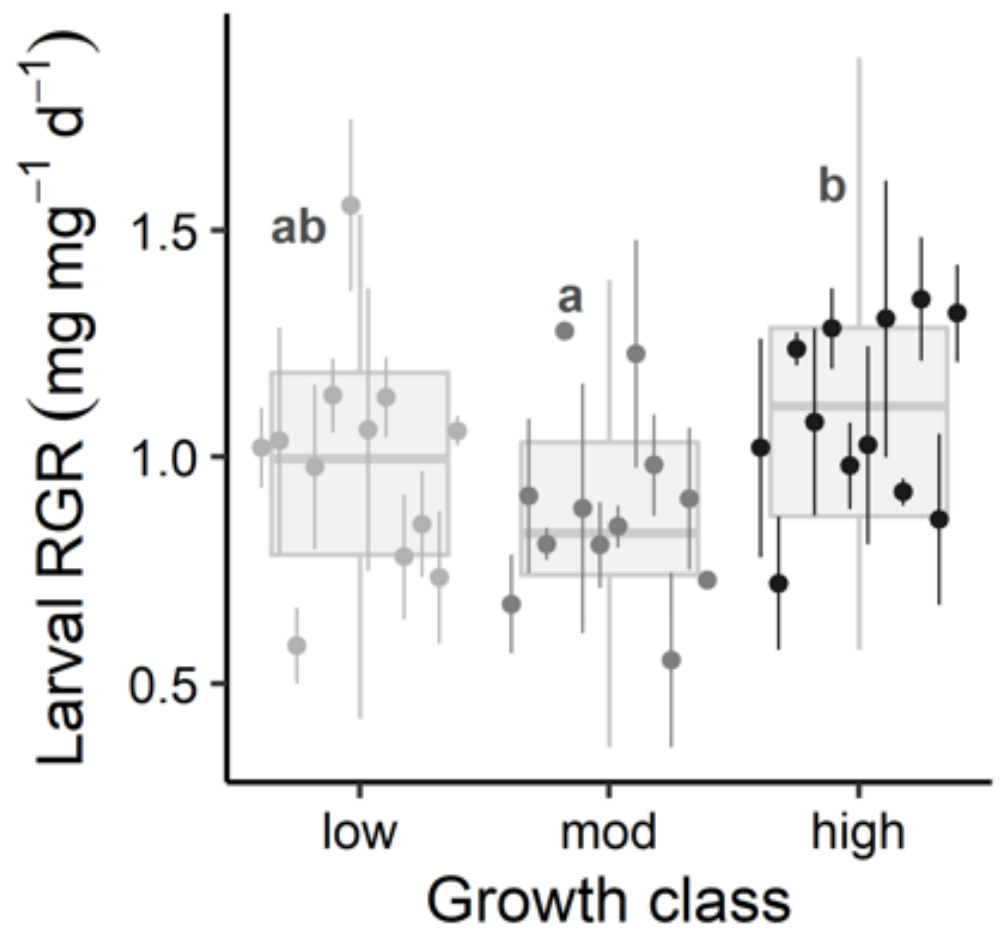

Figure 3

Variation in larval growth rate among aspen growth classes. Formatting follows from Fig. 1. 


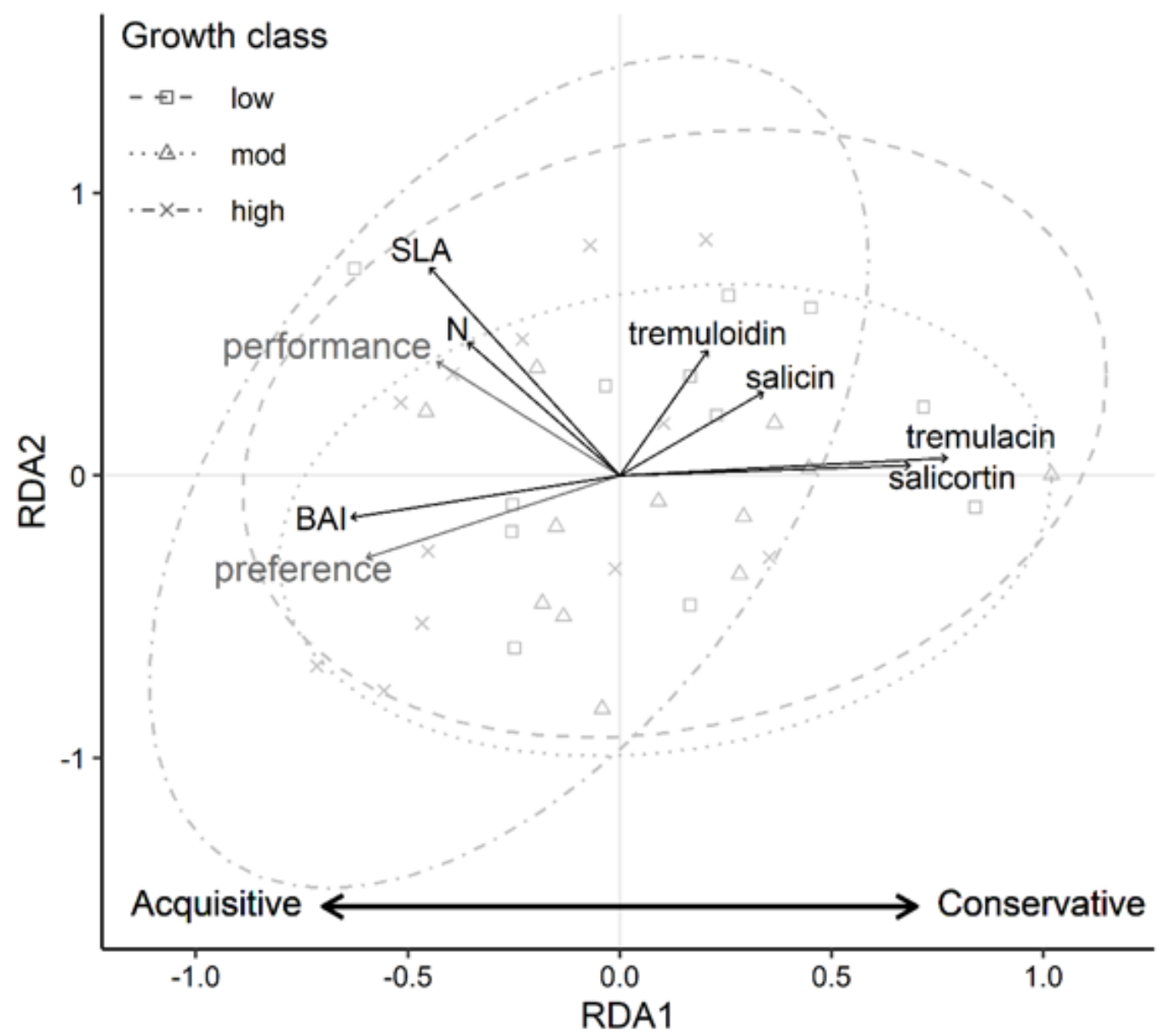

Figure 4

RDA plot of insect responses (gray vectors) and tree trait predictors (black vectors). Angles between vectors are approximately proportional to correlations between variables $\left(90^{\circ}\right.$ : none, $>90^{\circ}$ : negative, $<90^{\circ}$ : positive) but see Table 4 for true correlations. Points represent genotypes. Ellipses encompass the expected phenotypes of each growth class. Axis RDA1 accounts for $24.2 \%$ of variation in larval responses and RDA2 accounts for $11.0 \%$. Black arrows at the bottom of the plot represent the LES.

\section{Supplementary Files}

This is a list of supplementary files associated with this preprint. Click to download.

- morrowetal2021ESMOecologiasubmission.pdf 